\title{
Involvement of P Glycoprotein from Human R7 Cells Derived from Erythroleukemia in Its Attachment to the Progesterone Binding Site
}

\author{
S. Seddiki*, H. Ould Cadi, T. Sahraoui, F. Z. El Kebir \\ Laboratory of Biology of Development and Differentiation, Department of Biology, Faculty of Natural Science and Life, \\ University of Oran 1-Ahmed Ben Bella, Oran, Algeria \\ Email: *sonia13_2000@yahoo.fr
}

How to cite this paper: Seddiki, S., Cadi, H.O., Sahraoui, T. and El Kebir, F.Z. (2018) Involvement of $\mathrm{P}$ Glycoprotein from $\mathrm{Hu}-$ man R7 Cells Derived from Erythroleukemia in Its Attachment to the Progesterone Binding Site. Journal of Cancer Therapy, 9 , 299-306.

https://doi.org/10.4236/jct.2018.93027

Received: January 31, 2018

Accepted: March 23, 2018

Published: March 26, 2018

Copyright $\odot 2018$ by authors and Scientific Research Publishing Inc. This work is licensed under the Creative Commons Attribution International License (CC BY 4.0).

http://creativecommons.org/licenses/by/4.0/

(C) (i) Open Access

\begin{abstract}
Treatment of cancer with chemotherapy often faces drug resistance issues, which can stop after a period of remission. This resistance is due to several mechanisms; among them, the most important is the one in relation with the overexpression of the P glycoprotein (Pgp) produced by the mdr 1 gene. This gene confers to cells the multidrug resistance (MDR) phenotype in the setting of treatment for many cancers (leukemia-lymphoma...). The aim of this study was to investigate the binding site of $\mathrm{P}$ glycoprotein by affinity labeling in order to synthesize effective inhibitors on chemotherapeutic drugs efflux. The first objective was to increase $\mathrm{P}$ glycoprotein concentration in R7 cells by treating them with doxorubicin to obtain human Pgp rich fractions. The second consisted in characterizing the progesterone binding site on Pgp by affinity photolabeling with tritiated azidopine on the one hand, and by western-blot transfer with C219 antibody on the other hand. Our results indicate a significant increase in the level of expression Pgp in R7 cells treated with 1 and $2.5 \mathrm{nM}$ doxorubicin, and clearly show enrichment in Pgp of doxorubicin treated R7 cells.
\end{abstract}

\section{Keywords}

P Glycoprotein, Doxorubicin, Tritiated Azidopine

\section{Introduction}

The anarchic development of tumor cells and their resistance to treatments are responsible for the therapeutic failure of the cancers treatment by chemotherapy [1]. This phenomenon remains a very active field of research which has known a big development since scientists assumed existence of unknown agents responsi- 
ble for this resistance [2]. It is only in 1974 that Doctor Victor Ling and his collaborators [3] suggested that a membrane protein, the glycoprotein P, over expressed in most of cancers cells treated by cytotoxic agents could be responsible for the existence of resistance to chemotherapy. Glycoprotein $\mathrm{P}$ is a membrane protein with molecular mass between 170 and $180 \mathrm{KDa}$ [4]. It constituted of two homologues parts, each containing six hydrophobic transmembrane segments involved in cytotoxic drugs transport and one cytoplasmic part involved in ATP binding and hydrolysis. The two homologues parts are separated by a phosphorylatable area called "Linkers region" [5]. This protein gets chemotherapeutic drugs outside tumor cells through a pumping action [4]. In 1979, a fraction of gene was introduced by Doctor Jack Riordan. This has greatly advanced scientists researches who attempt to precise the structure and function of glycoprotein $\mathrm{P}$. The multidrug resistance (MDR) phenotype is characterized by resistance to chemotherapy treatments acquired by cancerous cells treated by cytotoxic drugs [6]. This resistance is said multiple because cancerous cells with MDR phenotype are resistant to a lot of chemotherapeutic drugs. This cellular multi-resistance is based on some mechanisms implementation, among which one of the most important is overexpression of membrane proteins, including the glycoprotein P encoded by the gene mdr 1 [7] [8]. The dominant characteristic of MDR phenotype cells is accumulation decrease of cytotoxic drugs inside cells. Scientists continue to search for new methods of treating cancer without a increase potentially harmful anticancer drugs allowing better control of drug resistance and cancer cell proliferation [9]. That's why one of the most important research focuses is development of new modulator which, by acting on glycoprotein $\mathrm{P}$, could decrease chemotherapy drugs efflux.

\section{Material and Methods}

\subsection{Preparation of the Membrane of (Pgp)}

R7 cells over expressing the PgP are derived from the K 562 cell-line obtained in a patient affected with erythroleukemia. These cells initially weakly express the Pgp. They are made resistant to doxorubicin by treatment with this one.

\subsection{Cellular Culture of the $\mathbf{R} 7$ Cell-Line in Presence of Doxorubicin}

R7 cells are cultivated in RPMI medium prepared by adding about $750 \mathrm{ml}$ of sterile water, $100 \mathrm{ml}$ of RPMI medium (10x) supplemented with $10 \mathrm{ml}$ of $30 \% \mathrm{glu}$ cose, $10 \mathrm{ml}$ of $200 \mathrm{mM}$ L glutamine, $2 \mathrm{ml}$ of penicillin solution, $2 \mathrm{ml}$ of nystatin solution, 0.9 M sodium bicarbonate solution; and completed until $1000 \mathrm{ml}$ sterile water. The $\mathrm{pH}$ of the medium is adjusted by addition of $2 \mathrm{~N}$ sodium hydroxide solution until the pink color $(\mathrm{pH}=8)$ is obtained. $\mathrm{R} 7$ cells were successively cultivated in presence of increasing dose of $0.5,1$ and $2.5 \mathrm{nM}$ doxorubicin in order to increase Pgp concentration in the cells. Culture media are renewed every 48 hours because of doxorubicin half-life. 


\subsection{Preparation of the Frozen Cellular Lysate}

Cell fluid is deposited in $50 \mathrm{ml}$ vials and, using a cell counter, density of R7 cells in each vial was measured. The cell pellets (36X.10 cells) were centrifuged during 10 min and washed with cold PBS buffer pH 7.4 and then centrifuged a second time during $5 \mathrm{~min}$. The collected pellets were suspended in lysis buffer. The lysate then was frozen in liquid nitrogen.

\subsection{Preparation of Membrane Fractions}

The cell lysate was defrosted, crushed with Potter and sonicated. The resultant homogenate was centrifuged during $10 \mathrm{~min}$ at $4^{\circ} \mathrm{C}$, the supernatant is recovered and subjected to ultracentrifugation during $30 \mathrm{~min}$ at $4^{\circ} \mathrm{C}$, and the pellet then was taken up in $10 \mathrm{mM}$ Tris $\mathrm{pH} 7.4$ containing $200 \mu \mathrm{l}$ of sucrose. These membrane fraction were stored in aliquots at $-80^{\circ} \mathrm{C}$. Control of Pgp presence in the membrane fractions was performed by Western-Blot with C219 antibody.

Transfer of polyacrylamide gel proteins on a nitrocellulose membrane after 7.5\% SDS electrophoresis was performed in a transfer solution $(0.025 \mathrm{M}$ Tris- $\mathrm{HCl} \mathrm{pH} \mathrm{8.3,0.2} \mathrm{M} \mathrm{glycine,} \mathrm{20 \%} \mathrm{methanol)} \mathrm{at} 250 \mathrm{~mA}$ during two hours. The nitrocellulose membrane then was treated in several steps:

The membrane first underwent saturation with the solution during one hour at room temperature, then a first incubation with the solution containing the first antibody C219 during 1 hour at room temperature or overnight at $4^{\circ} \mathrm{C}$, under soft agitation; followed by a series of washes $(3 \times 15$ minutes $)$ with TBS-Tween buffer $(50 \mathrm{ml})$ at room temperature.

Then it underwent a second incubation with the second antibody solution (anti IgG of mouse coupled with peroxidase, $0.025 \%$ ) during $1.5 \mathrm{~h}$ at room temperature under soft agitation, then another series of washes $(3 \times 15$ minutes) by TBS-Tween, $(50 \mathrm{ml})$ at room temperature. Finally, revelation was performed by chemoluminescence with the ECL + kit (Amersham); the membrane was deposited in the mixture of the revelation (solution A with solution B), letting react for a few minutes, then the reagents were removed with paper towels; the membrane was covered with a cellophane film and the whole was placed in an autoradiography cassette.

In the darkroom, a film was placed on the membrane and the revelation of the film was done by 10 minutes of exposure at room temperature.

The characterization of the Pgp binding site was performed by affinity photolabeling with tritiated azidopine (Figure 1). Tritiated azidopine is a hydrophobic photomarker which specifically binds to Pgp allowing the formation of a covalent bond with it by irradiation. $20 \mu \mathrm{l}$ aliquots of the different membrane fractions of Pgp were placed in irradiation tubes which are then incubated with tritiated azidopine in the dark at room temperature for two hours and then degassing under argon was performed at $4^{\circ} \mathrm{C}$ during 15 minutes. Then these membrane fractions underwent UV irradiation under argon for 15 minutes to generate a nitrene radical which allows formation of a covalent bond of 


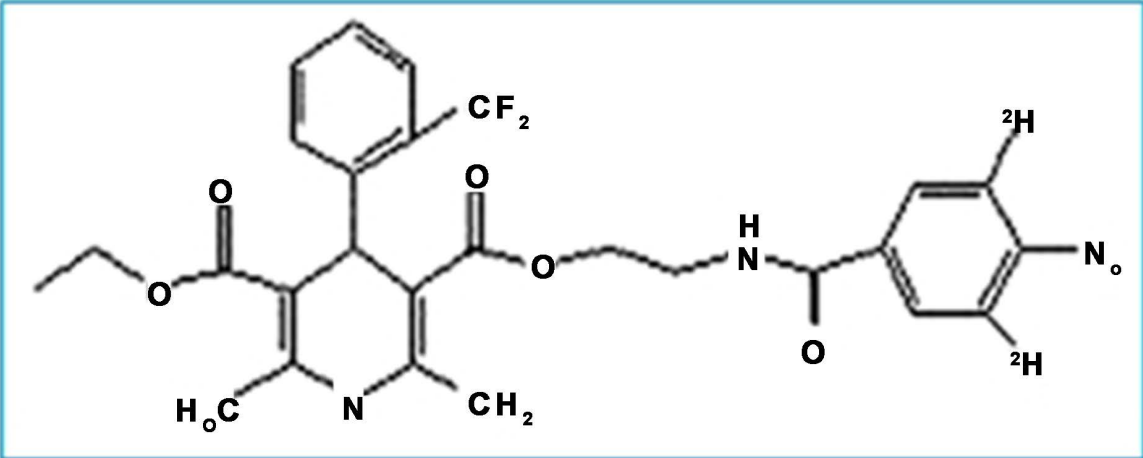

Figure 1. Structure of tritiatedazidopine.

azidopine with Pgp. The photolabelled samples were analyzed on SDS-PAGE $7.5 \%$ gel by autoradiography.

\section{Results}

\subsection{Highlighting Pgp Concentration Increase in R7 Cells Treated with Doxorubicin}

R7 cells derived from the K562 cell-line obtained from a patient affected with erythroleukemia were made resistant to doxorubicin by a unique dose of $0.5 \mathrm{nM}$, in order to overexpress Pgp. R7 cells were first in a continuous manner treated with doxorubicine $0.5 \mathrm{nM}$ in the culture medium. After adaptation to these new conditions of culture, R7 cells then were successively treated with doxorubicin doses at 1 and $2.5 \mathrm{nM}$. Results of this work showed that the significant Pgp concentration increase is noted in cells treated with 1 and $2.5 \mathrm{nM}$ of doxorubicin.

\subsection{Control of Pgp Presence by Western Blot in the Membrane Fractions Common Mistakes}

Figure 2 represents results of Western Blot showing an increase of quantity of Pgp in cells treated with doxorubicin as compared to R7 cells which weren't treated and for which presence of Pgp is hardly visible. A moderate increase was observed for cells treated with $0.5 \mathrm{nM}$ of doxorubicin, while treatment with 1 $\mathrm{nM}$ causes another increase of Pgp level expression. The fraction treated with 2.5 $\mathrm{nM}$ (seems to) present an important increase of Pgp which appears on Western Blot.

\subsection{Photolabeling of Membrane Fractions with Tritiated Azidopine}

The tritiated azidopine was used to characterize R7 cells membrane fractions Pgp treated by doxorubicin. The autoradiogram on SDS-PAGE gel 7.5\% revealed an intense $170 \mathrm{kDa}$ molecular mass radioactive band on fractions treated with doxorubicine 1 and $2.5 \mathrm{nM}$ which corresponds to the mass of Pgp. Moreover, a less intense $170 \mathrm{kDa}$ radioactive band was observed for the membrane fraction treated with doxorubicine $0.5 \mathrm{nM}$. These results confirm that fractions treated with doxorubicine 1 and $2.5 \mathrm{nM}$ are enriched with Pgp. 


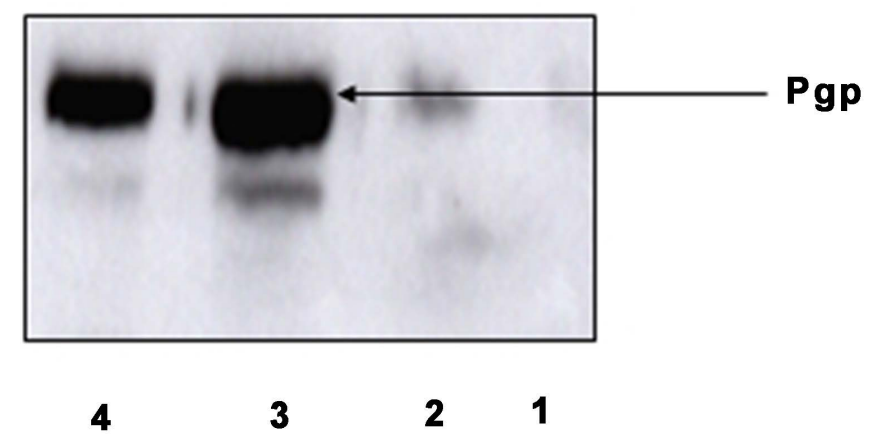

Figure 2. Western Blot of membrane fractions. Lane 1: Crude R7 cells membrane fractions; Lane 2: Crude R7 cells membrane fractions treated with doxorubicin $0.5 \mathrm{nM}$; Lane 3: Crude R7 cells membrane fraction streated with doxorubicin $1 \mathrm{nM}$; Lane 4: Crude R7 cells membrane fractions treated with doxorubicin $2.5 \mathrm{nM}$.

\section{Discussion}

A number of tumor cells treated with cytotoxic molecules resist after some time of therapy. This resistance corresponds to acquisition by these cells of MDR phenotype, which confers them multiple resistances to different drugs [10]. We supposed that this resistance could probably correspond to the acquisition of this phenotype by a cell and is correlated with the overexpression of the P glycoprotein, responsible for the flowback of chemotherapy drugs outside the cell [11].

Number of research works were conducted to find compounds which would be able to inhibit the efflux of chemotherapeutic drugs by P-glycoprotein. Many compounds used in different therapeutic indications were capable to reverse in vitro multidrug resistance. Among these are immunosuppressant agents such as cyclosporin A, antibiotics, calcium channel blockers (such as verapamil), steroid hormones such as progesterone and RU486 [12] [13] [14].

Studies dedicated to functioning mechanism modulators assessment tried to determine whether modulators act as competitive inhibitors of drug transport, or whether there is a modulator binding site different from the binding site of carried substrates. To date, results although conflicting rather suggest existence of two distinct sites as shown by Barnes and collaborators [15] who indicated that these two sites would be cooperative. However, if the existence of two sites seems quite possible, it is not certain that one of the sites only binds the carried substrates, and the other only the modulators. Another important controversy about the functioning of $\mathrm{P}$ glycoprotein is structures that are recognized as being able to be substrates and those which can be not carried modulators, which maintains an uncertainty on their binding in one or the other of the two sites [16] [17] [18].

The aim of our study was to characterize the human glycoprotein P binding site by affinity labeling with hydrophobic photomarkers in order to determine the location and topology of steroid modulator binding site. In order to increase 


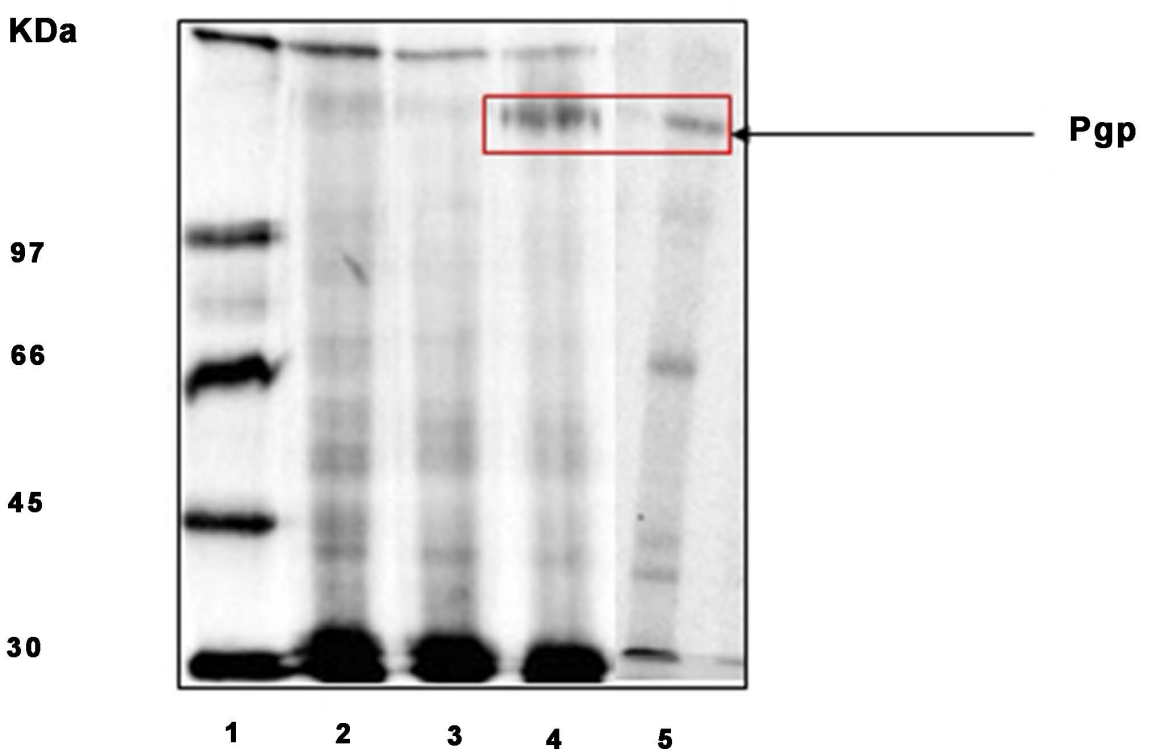

Figure 3. Photolabeling of membrane fractions with tritiatedazidopine. Lane 1: Molecular weight markers. Lane 2: Crude R7 cells membrane fractions; Lane 3: R7 cells membrane fractions treated with $0.5 \mathrm{nM}$ doxorubicin. Lane 4: R7 cells membrane fractions treated with $1 \mathrm{nM}$ doxorubicin. Lane 5: R7 cells membrane fractions treated with $2.5 \mathrm{nM}$ doxorubicin

the Pgp expression level in R7 cells, we tried to treat them with increasing doses of doxorubicin at $0.5,1$ and $2.5 \mathrm{Nm}$. In order to increase the level of Pgp expression in R7 cells, we tried to treat them with increasing doses of doxorubicin. For this, the cells were successively cultured in presence of doxorubicin at $0.5,1$ and $2.5 \mathrm{nM}$. For each concentration of doxorubicin, the cells have a more or less survival time, then eventually get used to the treatment and begin again to multiply. R7 cell lines, $0.5,1$, and $2.5 \mathrm{nM}$, were obtained in two months. Overexpression of Pgp was first characterized by Western Blot with the C219 antibody. Results showed a growing increase of Pgp in doxorubicin 0.5, 1 and 2.5 cells membrane fractions. Affinity photolabeling with tritiated azidopine showed greater covalent binding in the membrane fractions of cells treated with 1 and $2.5 \mathrm{nM}$ doxorubicin, which confirms results of Western-Blot, and suggests we well obtained Pgp expression increase by treatment with doxorubicin at these doses. These results are similar to those already published, showing a significant increase in Pgp expression level in membrane fractions treated with doxorubicin [19] [20] (Figure $3)$.

\section{Conclusions}

Our results highlight the Pgp expression increase level in R7 cells treated with 1 and $2.5 \mathrm{nM}$ doxorubicin. These results clearly show enrichment in Pgp of R7 cells treated with doxorubicin. The presence of Pgp in these cells was characterized by Western Blot with C219 antibody, and by affinity photolabeling with tritiated azidopine as well which showed a covalent binding with these cells. 
Our work, which aimed to study the binding site of $\mathrm{P}$ glycoprotein by affinity labeling to synthesize effective inhibitors on the efflux of chemotherapeutic drugs, allowed us to reach our two objectives which were to increase the concentration of P glycoprotein (Pgp) in R7 cells treated with doxorubicin to obtain Pgp rich human fractions, and to characterize the progesterone binding site on Pgp by affinity photolabelling with tritiated azidopine on the one hand, and by Western blot with C219 antibody on the other hand.

In prospect of this study, we will continue this work by preparing new cell lines obtained in presence of higher concentrations of doxorubicin, and by preparing steroid photomarkers having hydrophobic photoactivatable groups substituted at the end of link in C11-hydroxyl progesterone; these will be done to further explore the progesterone binding site on Pgp and thereby select the most appropriate chemosensitizing molecules.

\section{References}

[1] Higgins, C.F. (1992) ABC Transporters from Microorganisms to Man. Annual Review of Cell Biology, 8, 67-113. https://doi.org/10.1146/annurev.cb.08.110192.000435

[2] Baggetto, L.G. (1997) Novel Proteins Different from P-Glycoprotein, Implicated in the Multichimoresistance of Human Cancers. Cancer Bulletin, 84, 385-390.

[3] Ling, V. and Shapiro, B.A. (1994) ATP Ase Activity of Purified and Reconstituted P Glycoprotein from Chinese Hamster Ovary Cells. The Journal of Biological Chemistry, 269, 3745-3754.

[4] Gottesman, M.M. and Pastan, I. (1993) Biochemistry of Multidrug Resistance Mediated by the Multidrug Transporter. Annual Review of Biochemistry, 62, 385-427. https://doi.org/10.1146/annurev.bi.62.070193.002125

[5] Hrycyna, C.A. (2001) Molecular Genetic Analysis and Biochemical Characterization of Mammalian P Glycoprotein Involved in Multidrug Resistance. Seminars in Cell and Developmental Biology, 12, 247-256. https://doi.org/10.1006/scdb.2000.0250

[6] Saeki, T., Ueda, K., Tanigawara, Y., Hori, R. and Komano, T. (1993) Human P Glycoprotein Transports Cyclosporin A and FK506. The Journal of Biological Chemistry, 268, 60077-60080.

[7] Sandor, V., Fojo, T. and Bates, E. (1998) Future Perspectives for the Development of P-Glycoprotein Modulators. National Cancer Institues, 1, 190-200. https://doi.org/10.1016/S1368-7646(98)80039-3

[8] Vo, Q.D. and Gruol, D.J. (1999) Identification of P-Glycoprotein Mutations Causing a Loss of Steroïd Recognition and Transport. The Journal of Biological Chemistry, 274, 20318-20327. https://doi.org/10.1074/jbc.274.29.20318

[9] Endicott, J.A. and Ling, V. (1989) The Biochemistry of P-Glycoprotein Mediated Multidrug Resistance. Annual Review of Biochemistry, 58, 137-171. https://doi.org/10.1146/annurev.bi.58.070189.001033

[10] Jane,T.E., Merrit, J., Sullivan, A., Drew, L., et al. (1999) The Bisindolylmaleimide Protein Kinase C Inhibitor, Ro 32-2241, Reverse Multidrug Resistance in KB Tumour Cells. Cancer Chemotherapy and Pharmacology, 43, 371-378. https://doi.org/10.1007/s002800050909

[11] Shapiro, B.A. and Ling, V. (1997) Positively Cooperative Site for Drug Transport by 
P Glycoprotein with Distinct Drug Specifities. The Journal of Biochemistry, 250, 130-137.

[12] Perez, F.J., Conseil, G., Munoz, M., Perez, J.M., et al. (2003) RU 49953: A Non-Hormonal Steroid Derivative That Potently Inhibits P-Glycoprotein and Reverts Cellular Multidrug Resistance. CMLS, Cellular and Molecular Life Sciences, 60, 526-535. https://doi.org/10.1007/s000180300044

[13] Fleming, G.F., Amato, J.M., Agresti M. and Safa, A.R. (1992) Megestrol Acetate Reverses Multidrug Resistance and Interacts with P-Glycoprotein. Cancer Chemotherapy and Pharmacology, 29, 445-449. https://doi.org/10.1007/BF00684845

[14] Gruol, J.D., Zee, M.C., Trotter. J. and Bourgeois, S. (1994) Reversal of Multidrug Resistance by RU 486. Cancer Research, 54, 3088-3091.

[15] Barnes, M.K., Dickstein, B., Gordon, B., Fojo, T., et al. (1996) Steroid Transport Accumulation and Antagonism of P Glycoprotein in Multidrug-Resistant Cells. Biochemistry, 35, 4820-4827. https://doi.org/10.1021/bi952380k

[16] Mourez, M., Jéhanno, M., Hofnung, M. and Dassa, E. (2000) Role, Operation and Structure of Carriers ATP Binding Cassette (ABC). Médecine/ Science, 16, 386-394. https://doi.org/10.4267/10608/1658

[17] Maoqing, D., Penin, F. and Baggetto, L. (1996) Efficient Purification and Reconstitution of P Glycoprotein for Functional and Structural Studies. The Journal of Biological Chemistry, 271, 28875-28883. https://doi.org/10.1074/jbc.271.46.28875

[18] Sharom, F.J., Liu, R. and Romisicki, Y. (1998) Spectroscopic and Biophysical Approaches for Studying the Structure and Function of the P-Glycoprotein Multidrug Transporter. Biochemistry and Cell Biology, 76, 695-708. https://doi.org/10.1139/o98-075

[19] Sharom, F.J. (1997) The P-Glycoprotein Efflux Pump: How Does It Transport Drugs? The Journal of Membrane Biology, 160, 161-175. https://doi.org/10.1007/s002329900305

[20] Lai, G.M., Chen, Y.N., Mickley, L.A., Fojo, A.T. and Bates, S.E. (1991) P-Glycoprotein Expression and Schedule Dependence of Adriamycin Cytotoxicity in Human Colon Carcinoma Cell Lines. International Journal of Cancer, 49, 696-703. https://doi.org/10.1002/ijc.2910490512 